\title{
Localizing Muscles for Botulinum Toxin Treatment of Focal Hand Dystonia
}

\author{
C. Geenen, E. Consky and P. Ashby
}

\begin{abstract}
Background: There is currently no consensus on the best way to localize muscles in the forearm for botulinum toxin (BTX) injection. We devised a study to compare electromyography (EMG) with local stimulation through a cannula for localizing forearm muscles for botulinum toxin (BTX) injection, and for predicting the risk of unwanted weakness in non-target muscles. Methods: In 12 patients with focal hand dystonia a single "target" muscle, determined by clinical examination to contribute most to the dystonic hand posture, was selected for botulinum toxin injection. The patients were randomized into 2 treatment groups, one in which the target muscle was localized by recording the EMG signals during voluntary contractions ( 8 patients) and the other in which the target muscle was localized by local electrical stimulation (4 patients). The target muscle was then injected with a standardized dose of BTX. Results: At follow-up 3 weeks after BTX injection the target muscle was weakened in $7 / 12$ patients (4/8 of the EMG group, and $3 / 4$ of the stimulation group). Additional noninjected muscles, adjacent to the target muscle, were weakened in 5 of these 7 patients, presumably from diffusion of the toxin. Conclusions: Localization by stimulation is probably at least as good as EMG. Each technique has certain advantages. Weakness of "non-target" muscles was not consistently predicted by either EMG or stimulation suggesting that BTX diffuses farther than the volume conduction of EMG signals or the spread of effective stimulus current.
\end{abstract}

\begin{abstract}
RÉSUMÉ: Localisation des muscles impliqués dans la dystonie focale de la main en vue du traitement par la toxine botulique. Introduction: Il n'y a pas actuellement de consensus quant à la meilleure façon de localiser les muscles de l'avant-bras pour l'injection de toxine botulique (TXB). Nous avons élaboré une étude pour comparer l'électromyographie avec la stimulation locale au moyen d'une canule pour la localisation des muscles de l'avantbras dans le but d'injecter la TXB et pour prédire le risque de faiblesse inopportune de muscles qui n'étaient pas ciblés. Méthodes: Nous avons choisi un seul muscle cible, identifié par examen clinique comme contribuant le plus à la posture dystonique de la main, chez 12 patients souffrant d'une dystonie focale de la main. Les patients ont été randomisés en deux groupes, l'un chez qui le muscle cible était localisé par l'enregistrement de signaux EMG pendant des contractions volontaires (8 patients) et l'autre chez qui le muscle cible était localisé par stimulation électrique locale (4 patients). Une dose standard de TXB était ensuite injectée dans le muscle cible. Résultats: Au moment du suivi effectué 3 semaines après l'injection de TXB, le muscle cible était affaibli chez 7 patients sur 12 (4 sur 8 du groupe avec EMG et 3 sur 4 du groupe avec stimulation). D'autres muscles non injectés adjacents au muscle cible étaient affaiblis chez 5 de ces 7 patients, présumément par diffusion de la toxine. Conclusions: La localisation par stimulation est probablement aussi bonne que la localisation par EMG. Chaque technique a certains avantages. La faiblesse des muscles non ciblés n'était pas prédite de façon fiable par EMG ou par stimulation, ce qui suggère que la TXB diffuse plus loin que la conduction volumétrique des signaux EMG ou que la diffusion du courant d'excitation efficace.
\end{abstract}

Can. J. Neurol. Sci. 1996; 23: 194-197

Focal hand dystonia is characterized by involuntary muscle contractions which result in abnormal posturing of the fingers, wrist or forearm, and impaired motor control during skilled manual tasks. "Writer's cramp" is the commonest form of hand dystonia but many other subtypes have been described. Hand dystonia has been classified as "simple" (in which there is difficulty in performing one task only), "dystonic" (in which the muscle spasms occur with several tasks from the outset), or "progressive" (in which there is difficulty performing an increasing number of new tasks).' Electrophysiological studies have demonstrated co-contraction of agonist and antagonist muscles, overflow of activity to other remote muscles and defects in the selection of muscles for the specific task. ${ }^{2}$

Drug therapy, relaxation techniques, the use of writing devices and various other therapies are rarely successful in reducing disability. ${ }^{1,3}$ Botulinum toxin (BTX) therapy has been

\footnotetext{
From the Division of Neurology and EMG laboratory, The Toronto Hospital. and the University of Toronto, Toronto. RECEIVED JUNE 21, 1995. ACCEPTED IN FINAL FORM MARCH 26, 1996. Reprint requests to: Peter Ashby MD. The Toronto Hospital, 399 Bathurst Street, Edith Cavell 8-023, Toronto, Ontario, Canada M5T 2S8
} 
demonstrated to provide safe and effective treatment of a number of focal dystonias previously refractory to medical or surgical therapy. ${ }^{5}$ Several open-label studies ${ }^{6-8}$ and one double-blind study ${ }^{9}$ using BTX report a beneficial response in $67 \%-82 \%$ of patients. Current opinion suggests that BTX therapy be considered as first-line treatment for focal hand dystonia. ${ }^{10}$

Published protocols have varied widely in methodology including the clinical or EMG criteria for muscle selection, the injection technique, and the dose employed. The effectiveness of BTX therapy for focal hand dystonia may depend to a great extent how discretely the appropriate target muscles for injection are localized and the extent to which they are weakened. Clinical improvement appears to be significantly correlated with post-injection weakness. ${ }^{9,11}$

There is currently no consensus regarding the optimal method of localizing muscles within the forearm for injection. Most studies have used surface landmarks, needle movement during passive muscle stretch, EMG, or a combination of these techniques. Patients with dystonia, however, are often unable to activate single muscles in isolation so that EMG activity, or needle deflection produced by co-contracting non-target muscles, may be misleading. It has been our experience that stimulation of muscles through the EMG electrode can also effectively identify target muscles.

A study was therefore devised to compare the utility of EMG and stimulation for localizing muscles for BTX injection and for predicting the risk of unwanted weakness in non-target muscles.

\section{METHODS}

\section{Choice of patients, initial assessment}

Twelve patients with focal hand dystonia were recruited from a movement disorder practice and informed consent was obtained. A single muscle for injection, the "target muscle", determined by clinical observation and review of videotape material to contribute most to the dystonic posturing, was selected in each patient. Muscle strength (MRC grading), of all muscles of interest in the upper limb was graded by two observers independently within one week before injection.

\section{Stimulation and recording}

A $5 \mathrm{~cm}$ cannula, insulated except at the tip, (Dantek $13 \mathrm{R} \mathrm{19)}$ was used as the active electrode for recording and the cathode for stimulation. A surface electrode placed $4 \mathrm{~cm}$ distal to the site of insertion of the cannula along the course of the muscle served as the indifferent electrode. EMG signals were amplified using band pass $10 \mathrm{~Hz}$ to $1 \mathrm{KHz}$ and monitored with an oscilloscope and loudspeaker. Constant current stimuli (pulse width $0.1 \mathrm{~ms}$, intensity 0.5 to $24 \mathrm{~mA}$ ) were generated by a Dantek Neuromatic.

\section{Injection Procedure}

The patients were randomized using a table of random numbers into 2 treatment groups. In the first group, the target muscle was localized by EMG. The subject was asked to activate the target muscle and then other adjacent muscles in isolation while an EMG cannula was positioned to record the sharpest EMG potentials from the target muscle. The quality of the EMG signals recorded from neighbouring muscles with the needle elec- trode at this site was then noted. After the "best" localization had been achieved, the effects of stimulation at that same site were noted. The stimulus intensity was increased in increments of 0.5 $\mathrm{mA}-3 \mathrm{~mA}$ and the muscles recruited at each intensity were observed until no additional muscles were recruited after 3 increments, or when an intensity of $24 \mathrm{~mA}$ was reached. The EMG recording was then repeated to ensure that the needle had not moved and BTX was injected into the target muscle through the EMG cannula.

In the second group, the target muscle was localized by stimulation. The method was as described above except that the needle was relocated until the target muscle was the first muscle to be activated at the lowest threshold. The stimulus intensity was then increased and the threshold of adjacent muscles was noted. The quality of EMG activity from the voluntarily activated target muscle and neighbouring muscles was recorded without moving the needle. The needle location was then re-confirmed by stimulation and BTX was injected into the target muscle.

EMG localization was graded based on the quality of EMG signals, as follows: $3=\mathrm{crisp}, 2=\mathrm{less}$ crisp, $1=$ distant, $0=\mathrm{absent}$ EMG activity. The effect of stimulation was graded as follows: 3 $=$ the muscle was the first and only muscle to be activated at low threshold, 2 = the muscle was the second muscle activated as the stimulus intensity was increased, $1=$ the muscle was the third muscle activated, $0=$ there was no activation of the muscle even at the highest stimulus intensity.

\section{Injection of Botulinum Toxin}

25 units of botulinum toxin $A$, reconstituted at a concentration of 10 units per $0.1 \mathrm{cc}$, was injected into each target muscle except for one patient in whom a single muscle fascicle (FDS-2) was injected with 10 units. A flush of $0.1 \mathrm{cc}$ normal saline followed each injection.

\section{Follow-up Assessment}

MRC grading of the strength of all muscles of the injected limb was repeated three weeks post-injection independently by the same observers, one of whom was blinded to the method of target muscle localization. A target muscle was described as being "hit" if both observers agreed that the strength of the target muscle decreased by at least one grade on the MRC scale. Non-target muscles were described as being weakened if both observers agreed that strength decreased by one or more grades on the MRC scale. Non-target muscles were described as "adjacent" if they shared a common border with the target muscle or "distant" if they did not. The patients" opinion about their dystonia was also solicited and recorded. This was scored as "improved" or "not improved".

\section{Results}

A total of 12 patients were studied, 5 female and 7 male, aged 29-83 years. Seven patients had never received BTX injections before; 5 had received injections to the target muscle 5-9 months previously. No patients were on anticholinergic or other anti-dystonia medications. The target muscles selected are shown in Table 1. Eight patients were randomized to EMG localization, and four patients to localization by stimulation. No patients complained of pain during manipulation of the cannula, and none withdrew from the study. 


\section{Effects on target muscle (Table 1)}

The target muscle was weakened ("hit") in 4 of the 8 patients in whom EMG localization was employed. Reasons why the target muscle was not weakened in 4 patients may include : 1) Insufficient dose of botulinum toxin. 2) Maintenance of strength by non-injected synergist muscles, (for example, normal index finger extension maintained by EDC-2 when EIP was injected). 3) Injection superficial to the muscle

Table 1: Effects on Target Muscles.

\begin{tabular}{|c|c|c|c|c|c|}
\hline $\begin{array}{l}\text { Target } \\
\text { Muscle }\end{array}$ & $\begin{array}{c}\text { Total } \\
\text { Injected }\end{array}$ & $\begin{array}{c}\text { Hits by EMG } \\
\text { Total EMG }\end{array}$ & $\begin{array}{c}\text { Hits by Stim } \\
\text { Total Stim }\end{array}$ & Total Hits & $\begin{array}{c}\text { Subjective } \\
\text { Improvement }\end{array}$ \\
\hline FCU & 4 & $\frac{1}{2}$ & $\frac{2^{*}}{2}$ & $\frac{3}{4}$ & $\frac{2}{4}$ \\
\hline FCR & 1 & $\frac{0 * *}{1}$ & & $\frac{0}{1}$ & $\frac{1}{1}$ \\
\hline FDS - 2 & 1 & & $\frac{0}{1}$ & $\frac{0}{1}$ & $\frac{0}{1}$ \\
\hline ECU & 2 & $\begin{array}{l}2 \\
2\end{array}$ & & $\frac{2}{2}$ & $\frac{2}{2}$ \\
\hline ECR & 2 & $\frac{1}{2}^{*}$ & & $\frac{1}{2}$ & $\frac{0}{2}$ \\
\hline EIP & 2 & $\frac{0}{1}$ & $\frac{1}{1}$ & $\frac{1}{2}$ & $\frac{1}{2}$ \\
\hline Totals & 12 & $\frac{4}{8}$ & $\underline{3}$ & $\frac{7}{12}$ & $\frac{6}{12}$ \\
\hline
\end{tabular}

* Patient's target muscle weakened but no subjective improvement.

** Patient subjectively improved despite no weakening of target muscle.

Table 2. Effects on Other Muscles.

\begin{tabular}{|c|c|c|c|c|c|}
\hline $\begin{array}{l}\text { Target } \\
\text { Muscle }\end{array}$ & $\begin{array}{c}\text { Total } \\
\text { Injected }\end{array}$ & $\begin{array}{c}\text { Target Hit } \\
\text { Alone }\end{array}$ & $\begin{array}{c}\text { Target plus } \\
\text { Other(s) } \\
\text { Weakened }\end{array}$ & $\begin{array}{c}\text { Only other(s) } \\
\text { Weakened }\end{array}$ & $\begin{array}{l}\text { No Muscle } \\
\text { Weakened }\end{array}$ \\
\hline $\mathrm{FCU}$ & 4 & 1 & 2 & & 1 \\
\hline FCR & 1 & & & 1 & \\
\hline FDS-2 & 1 & & & 1 & \\
\hline ECU & 2 & 1 & 1 & & \\
\hline ECR & 2 & & 1 & & 1 \\
\hline EIP & 2 & & 1 & & 1 \\
\hline Totals & 12 & 2 & 5 & 2 & 3 \\
\hline \multicolumn{2}{|c|}{ Abbreviations: } & $\begin{array}{l}\text { FCU } \\
\text { FCR } \\
\text { FDS-2 } \\
\text { ECU } \\
\text { ECR } \\
\text { EIP }\end{array}$ & $\begin{array}{l}\text { - Flexor carpi } \\
\text { - Flexor carpi } \\
\text { - Flexor digito } \\
\text { - Extensor car } \\
\text { - Extensor car } \\
\text { - Extensor ind }\end{array}$ & $\begin{array}{l}\text { ulnaris } \\
\text { radialis } \\
\text { rum superficia } \\
\text { pi ulnaris } \\
\text { pi radialis } \\
\text { icis proprius }\end{array}$ & lis, fascicle 2 \\
\hline
\end{tabular}

(for example one of each of the 2 FCU and ECR injections in which no muscle was clinically weakened). Formation of antibodies was not felt to be the cause in those patients who developed no weakness, as one patient had never been injected before, and the other two have subsequently had other injections which have resulted in weakness.

In the 4 patients in whom stimulation was used to localize the target muscle, it was weakened ("hit") in 3 . The only failure was FDS-2. This was predicted by the difficulty encountered in localizing this fascicle and the relatively poor scores (stimulation $=2 / 3$, EMG $=1 / 3$ ) when the cannula was in the best position we could achieve. We have encountered this difficulty in targetting FDS-2 in other non-study patients utilizing either method. This is likely related to its position deep and distal to FDS-3.

\section{Effects on other muscles (Table 2)}

In 5 of the 7 patients in whom the target muscle was weakened there was also weakness of other, adjacent muscles. Two patients had only non-target muscles weakened, one in which a muscle adjacent to the target was weakened (target = FDS-2, muscle weakened = FDP-2) and the other, in which a distant muscle was weakened (target $=$ FCR, muscle weakened $=$ EPL). Three patients had no resultant muscle weakness from the injection.

\section{Prediction of weakness by EMG and Stimulation}

Localization scores for the target muscle were $3 / 3$ for EMG and $3 / 3$ for stimulation in the 7 patients who developed weakness of the target muscle. A total of 11 non-target muscles were weakened in 5 of these 7 patients. EMG and stimulation both predicted (by scores of 1,2, or 3) the possibility of diffusion of BTX to 2 of these non-target muscles and EMG alone predicted the possibility of diffusion in an additional 2 muscles. The weakening of the remaining 7 muscles was not predicted by either EMG or stimulation suggesting that the diffusion of BTX may be greater than the spread of EMG signals or stimulus current.

\section{Subjective Improvement (Table 1)}

Subjective improvement of hand writing was reported in 6 of the 12 patients. Two patients had target muscles hit but did not subjectively improve; one patient reported improvement despite no demonstrable weakness of the target muscle.

\section{Discussion}

Current issues in the treatment of focal hand dystonia with BTX include the choice of target muscle(s), methods of localizing the target muscle(s), the dose of BTX A to be administered, and the objective assessment of improvement in hand function and reduction in disability.

This study evaluated only methods for localizing target muscles for injection. One target muscle was selected for each patient so that the weakness produced in the target muscle and its neighbouring "muscles at risk" could be objectively assessed thereby allowing comparison of localizing methods. Optimal symptomatic improvement was not expected as several muscles usually contribute to dystonic posturing.

EMG is the most commonly used technique for localization but it has limitations. EMG signals can be misleading if the tip 
of the needle is in a synergist or a fixator muscle. Most importantly, patients with dystonia or spasticity may be unable to contract a target muscle in isolation, significantly limiting the localizing value in EMG. When a superficial muscle such as FCU is the target, the needle tip might be placed as superficial as possible to avoid diffusion to deeper muscles such as FDP. EMG signals may be recorded from FCU even when the needle tip is just outside the capsule. This may account for the failure to weaken these easily accessible muscles in our study.

Muscles can also be localized by stimulating through the tip of the cannula. This technique, too, may at times be misleading. The position of the indifferent electrode may alter the flow of current. Motor axons have lower thresholds than muscle fibres and if stimulated may cause contraction of several muscles, leading to erroneous conclusions. Axons in the median, anterior interosseous or ulnar nerves, for example, may be activated during the search for forearm flexor muscles. Observation of, or recording from the small hand muscles usually clarifies this matter.

Four of 8 patients localized by EMG had target muscles hit while 3 of 4 patients localized by stimulation had their target muscle hit. These numbers are too small for statistical comparison, but localization by stimulation appears to be at least as good as localization by EMG. In the present study, in all but 1 patient, both EMG and stimulation scores were the same $(3 / 3)$ for the target muscle indicating that the target muscle can be localized by either method. One technique, however, may have advantages over the other in particular clinical situations. Localization by stimulation may be preferable in dystonic patients in whom selective voluntary activation of individual muscles is impaired, while localization by EMG may be preferable when stimulation appears to be to activating motor axons.

Of the 7 patients who developed weakness of the target muscle there was also weakness of adjacent muscles. In some instances the proximity of these adjacent muscles to the needle tip was predicted by the EMG or stimulation scores but in the majority it was not. EMG was slightly better than stimulation at predicting that other muscles would be weakened $(4 / 11$ vs. $2 / 11$ ), but neither technique predicted weakness of the other 7 muscles, all but one of which was adjacent and deep to the target muscle. Evidently BTX diffuses further than the spread of EMG signals or stimulus current.

BTX is known to diffuse. In a rabbit model, Borodic et al. ${ }^{12}$ showed that botulinum toxin may diffuse up to $30-45 \mathrm{~mm}$ from the point of injection and may cause atrophy of muscle fibres across barriers of both fascia and bone. Chemodenervation has been measured showing that the gradient of denervation after BTX injection is dose dependent. ${ }^{13}$

Optimal clinical improvement was not the main expectation of this study. Only one muscle was injected and patients usually require more than one muscle to be weakened for clinical benefit. Subjective improvement, however, was noted in 6 of 12 patients $(50 \%)$. Interestingly, 2 patients had weakness of their target muscles but did not feel symptomatically improved. This may have resulted from either an inappropriate choice of target muscle or insufficient production of weakness. One patient subjectively improved despite no weakening of his target muscle, possibly the result of placebo effect or inappropriate target muscle selection.

\section{REFERENCES}

1. Sheehy MP, Marsden CD. Writer's cramp: a focal dystonia. Brain 1982; 105: 461-480.

2. Cohen LG, Hallett M. Hand cramps: clinical features and electromyographic patterns in a focal dystonia. Neurology 1988; 38: 1005-1012.

3. Koller WC, Vetere-Overfield B. Usefulness of a writing aid in writer's cramp. Neurology 1989; 39: 149-150.

4. Lang AET, Sheehy MP, Marsden CD. Acute anticholinergic action in focal dystonia. Adv Neurol 1983; 37: 193-200.

5. Report of the Therapeutics and Technology Assessment Subcommittee of the American Academy of Neurology. Assessment: the clinical use of botulinum toxin $\mathrm{A}$ in treating neurologic disorders. Neurology 1990; 40: 1332-1336.

6. Karp BI, Cole RA, Cohen LG, et al. Long term botulinum toxin treatment of focal hand dystonia. Neurology 1994; 44: 70-76.

7. Poungvarin N. Writer's cramp: the experience with botulinum toxin injections in 25 patients. J Med Assoc Thailand 1991; 74(5): 239-247.

8. Rivest J, Lees AJ, Marsden CD. Writer's cramp: treatment with botulinum toxin injections. Mov Disord 1991; 6(1): 55-59.

9. Yoshimura DM, Aminoff MJ, Olney RK. Botulinum toxin therapy for limb dystonias. Neurology 1992; 42: 627-630.

10. Karp BI, Hallett M. Botulinum toxin treatment of focal hand dystonia. In: Jankovic J, Hallett $\mathrm{M}$, eds. Therapy with Botulinum Toxin. New York: Marcel Dekker, 1994; 299-306.

11. Cohen LG, Hallett M, Geller BD, Hochberg F. Treatment of focal dystonias of the hand with botulinum toxin injections. J Neurol Neurosurg Psychiatry 1989; 52: 355-363.

12. Borodic GE, Joseph M, Fay L, Cozzolino D, Ferrante RJ. Botulinum A toxin for the treatment of spasmodic torticollis: dysphagia and regional toxin spread. Head and Neck 1990; 12: 392-398

13. Borodic GE, Ferrante R, Pearce LB, Smith K. Histologic assessment of dose-related diffusion and muscle fibre response after therapeutic Botulinum A toxin injections. Mov Disord 1994; 9(1): 31-39. 